\title{
Análise dos parâmetros mecânicos das misturas asfálticas com adição de óxidos metálicos
}

\author{
Analysis of mechanical parameters of \\ asphalt mixtures with addition of metal oxides
}

Flávia do Socorro de Sousa Carvalho ${ }^{1}$, Adriano Elísio de Figueiredo Lopes Lucena ${ }^{1}$, Osires de Medeiros Melo Neto ${ }^{1}$ Tassila Ramos Porto ${ }^{1}$ Thalita Maria Ramos Porto ${ }^{2}$

\footnotetext{
${ }^{1}$ Universidade Federal de Campina Grande-UFCG, Laboratório de Engenharia de Pavimentos-LEP, Rua Aprígio Veloso -nº 882, CEP: 58428- 830, Campina Grande, Paraíba, Brasil.

${ }^{2}$ Universidade Federal de Campina Grande-UFCG, Laboratório de Engenharia de Pavimentos-LEP, Rua João Carolino de Neto, $n^{\circ}$ 482, CEP: 58900- 000, Cajazeiras, Paraíba, Brasil.

e-mail:flaviasousa.ec@ hotmail.com; lucenafb@uol.com.br; osiresdemedeiros@gmail.com; tassilaporto@gmail.com; thalita_porto8@hotmail.com
}

\begin{abstract}
RESUMO
O pavimento asfáltico convencional, devido a sua coloração escura, absorve uma grande quantidade de energia que é transformada em calor, promovendo um enorme desconforto térmico para as pessoas que vivem nesse ambiente. Esse estudo trata da adição de pigmentos vermelhos na mistura asfáltica para obtenção de misturas asfálticas coloridas. A incorporação de óxidos metálicos em misturas asfálticas surge como uma forma de diminuir o albedo e consequentemente minimizar os efeitos da Ilha de Calor Urbana, além disso é esperado que não ocorra diminuição dos parâmetros mecânicos a fim de comprometer sua estrutura. Para realização desse estudo o ligante asfáltico utilizado na pesquisa foi submetido a ensaios de penetração, ponto de amolecimento e viscosidade rotacional e os agregados caracterizados com os ensaios de massa específica, granulometria e abrasão Los Angeles. A dosagem Marshall foi utilizada para produção dos corpos de prova a serem ensaiados para quantificação dos ensaios mecânicos: Resistência à Tração, Módulo de Resiliência e Estabilidade Marshall. As misturas com adição de 5\% de óxido metálico vermelho e amarelo apresentaram resultados de resistência inferiores à mistura de referência fabricada sem a adição do corante. No entanto, as misturas asfálticas com corante atendem aos requisitos mínimos exigidos por norma para todos os ensaios realizados, podendo ser utilizada em pavimentos coloridos com a finalidade de diminuir o efeito de Ilha de Calor Urbana.
\end{abstract}

Palavras-chave: óxido metálico. dosagem Marshall. mistura asfáltica.

\begin{abstract}
The conventional asphalt pavement, due to its dark coloring, absorbs a large amount of energy that is transformed into heat, promoting enormous thermal discomfort for people who live in that environment. This study deals with the addition of red pigments to the asphalt mixture to obtain colored asphalt mixtures. The addition of metallic oxides in asphalt mixtures appears as a way to reduce albedo and consequently minimize the effects of the Urban Heat Island, in addition it is expected that there will be no decrease in mechanical parameters in order to compromise its structure. To carry out this study, the asphalt binder used in the research was subjected to penetration tests, softening point and rotational viscosity and the aggregates characterized with the specific mass, particle size and abrasion tests in Los Angeles. Marshall dosage was used to produce the specimens to be tested to quantify the mechanical tests: Tensile Strength, Resilience Module and Marshall Stability. Mixtures with the addition of 5\% red and yellow metal oxide showed lower resistance results than the reference mixture manufactured without the addition of the dye. However, asphalt mixtures with dye meet the minimum requirements required by the standard for all tests performed, and can be used on colored floors in order to reduce the effect of Urban Heat Island.
\end{abstract}

Keywords: metallic oxide. Marshall dosage. asphalt mixtures. 


\section{INTRODUÇÃO}

Devido a coloração preta do ligante asfáltico, os revestimentos asfálticos apresentam altas temperaturas na sua superfície resultantes da absorção de grandes quantidades de radiação solar a qual é armazenada sob a forma de calor pelo revestimento. Assim, os pavimentos asfálticos tornam-se consideravelmente mais quentes que o meio ambiente. [1]

A diminuição da temperatura da superfície dos pavimentos asfálticos pode auxiliar fortemente na melhoria das condições térmicas em centros urbanos que sofrem com elevadas temperaturas. Isso pode ser obtido por meio da utilização de modificadores de ligante asfáltico capazes de melhorar seu desempenho térmico e reduzir a absorção de radiação solar.

É neste cenário que surge a alternativa da mudança na coloração do pavimento por cores mais claras, com objetivo de refletir a luz solar, sendo possível a partir do uso de pigmentos coloridos com intuito de aumentar o albedo das misturas asfálticas, ou seja, aumentar o quantitativo da refletividade solar total da superfície. [2]

Albedo é a razão entre a quantidade de luz que é difundida ou refletida por uma superfície e a quantidade de luz incidente sobre a mesma, quanto maior o albedo menor a temperatura da superfície e do ar. Aditivos de coloração juntamente com agregados adequados são utilizados para aumentar o albedo dos pavimentos [3].

Materiais de cores claras apresentam alta refletância de radiação solar e são tradicionalmente utilizados em assentamentos para contrabalancear o superaquecimento urbano [4]. O envelhecimento por radiação ultravioleta (UV) tem efeitos sobre o desempenho do ligante e da mistura asfáltica, principalmente à ductilidade a baixas temperaturas e a resistência à fadiga [5].

VILLENA [6] realizou um estudo com a utilização de óxidos metálicos mistos em misturas asfálticas a fim de mitigar a Ilha de Calor Urbana. A pesquisa apontou que misturas asfálticas coloridas atingem temperaturas até $3,7^{\circ} \mathrm{C}$ inferior do que as misturas convencionais, contribuindo para a diminuição da sensação térmica dos espaços externos e internos próximos ao local de aplicação.

A utilização de pigmentos orgânicos e inorgânicos em ligantes asfálticos proporcionam maior refletância. Os pigmentos inorgânicos incluem cromatos, óxidos, silicatos, boratos, sulfatos, fosfatos, metais e venadatos [7]. KARAHANCER [8] realizou um estudo com ligante asfáltico modificado com nanopartículas de óxido cuproso em teores de $1,5 \%, 3 \%$ e 4,5\% em misturas asfálticas à quente. As amostras com ligante modificado em todos os teores estudados apresentaram maior resistência à deformação permanente após envelhecimento em RTFOT quando comparadas ao ligante convencional. A mistura asfáltica modificada com $1,5 \%$ de óxido de zinco foi a que apresentou melhor resistência à fadiga e à tração indireta, dentre as analisadas.

O efeito de modificadores de superfície de nanopartículas de óxido de zinco nas propriedades de envelhecimento à radiação ultravioleta (UV) do ligante asfáltico foi analisado por LIU et al. [5] e os resultados apontaram que a adição das nanopartículas diminui o índice de carbonila da mistura asfáltica após o envelhecimento por UV, indicando boa resistência à radiação ultravioleta.

KARAHANCER et al. [9] desenvolveram um estudo com adição de nanopartículas de óxido de ferro em teores de $1 \%, 3 \%$ e $5 \%$ para analisar as propriedades reológicas do ligante asfáltico, assim como as propriedades mecânicas das misturas asfálticas mornas. O desempenho máximo à deformação permanente foi observado no ligante asfáltico com teor de $5 \%$, contudo os resultados de recuperação elástica para todos os ligantes modificados foram inferiores ao ligante convencional a 3,2 kPa. As Ilhas de Calor foram aumentadas pelo acréscimo de temperatura ocasionado pela adição do óxido de ferro. Ligante asfáltico modificado por politiofeno dopado com óxido de ferro foi estudado por MOUSAVI et al. [10] e seu estudo apontou uma melhoria no módulo de cisalhamento e resistência à deformação permanente.

PORTO [2] desenvolveu um estudo com adição de 5\% de óxido de ferro em misturas asfálticas a fim de verificar se a adição desse material reduz a temperatura da superfície e aumenta a refletância do pavimento asfáltico. Os resultados apontaram que o modificador melhorou as propriedades mecânicas das misturas, assim como a refletância do pavimento asfáltico em sua simulação.

Com base no exposto, este estudo tem como objetivo avaliar a adição de óxidos metálicos de ferro em misturas asfálticas por meio de ensaios mecânicos analisando a influência dos corantes nas respostas mecânicas das misturas e a viabilidade do seu uso nessas. 


\section{MATERIAIS E MÉTODOS}

Neste tópico são descritos os materiais e procedimentos realizados durante a fase experimental da pesquisa, realizados de acordo com normas estabelecidas pelo DNIT e pela ASTM.

\subsection{Materiais}

Na produção da mistura asfáltica do estudo foi utilizado Cimento Asfáltico de Petróleo CAP 50/70 concedido pela usina de beneficiamento da empresa Rocha Cavalcante, situada no município de Campina Grande - PB.

Os agregados graníticos e o pó de pedra foram cedidos pela pedreira da empresa Rocha Cavalcante da jazida situada em Campina Grande - PB. A amostra foi separada por quarteamento, método B da norma DNIT PRO 199/96 [11].

A areia e o fíler (Cal Hidratada CHI) utilizados no estudo foram obtidos no comércio local da cidade de Campina Grande - PB. A amostra de areia foi separada por amostragem de pilha de estoque em miniatura, método C da designação DNIT PRO 199/96 [11].

Dentre a diversidade de óxidos metálicos existentes, nesta pesquisa optou-se pelo uso dos óxidos que apresentam coloração vermelha e coloração amarela, devido aos bons resultados que VILLENA [5] e PORTO [2] obtiveram utilizando-os em seu trabalho. O óxido metálico obtido foi do tipo óxido de ferro do fabricante Lanxess, adquirido com um fornecer em João Pessoa que vende o óxido de ferro do mesmo fabricante que os utilizados pelos autores acima citados em suas pesquisas.

\subsubsection{Cimento asfáltico de Petróleo (CAP) e agregados}

A Tabela 01 apresenta as características do ligante asfáltico e os valores obtidos nos ensaios de Penetração e Viscosidade Rotacional dentro dos limites mínimos e máximos exigidos pela norma DNIT-EM 095/2006 [12]. Entretanto, no ensaio de Ponto de Amolecimento o valor não se classifica dentro do limite mínimo estabelecido em norma para o CAP 50/70.

Tabela 1: Propriedades do ligante asfáltico.

\begin{tabular}{c|c|c|c}
\hline ENSAIO & LIMITES & RESULTADO & NORMA \\
\hline $\begin{array}{c}\text { Penetração } 0.1 \mathrm{~mm} \\
\left(100 \mathrm{~g}, 5 \mathrm{~s} \text { a } 25^{\circ} \mathrm{C}\right)\end{array}$ & $50-70$ & 54,4 & $\begin{array}{c}\text { ASTM } \\
\text { D5:2019 } \\
{[13]}\end{array}$ \\
\hline Ponto de Amolecimento $\left({ }^{\circ} \mathrm{C}\right)$ & $\geq 46$ & 45,5 & $\begin{array}{c}\text { ASTM } \\
\text { D36:2014 } \\
{[14]}\end{array}$ \\
\hline Viscosidade Rotacional $(\mathrm{cP})$ & $\geq 274$ & $385,0\left(\mathrm{a} 135^{\circ} \mathrm{C}\right)$ & ASTM \\
& $\geq 112$ & $195,0\left(\right.$ à $\left.150^{\circ} \mathrm{C}\right)$ & $\begin{array}{c}\mathrm{D} 4402: 2015 \\
{[15]}\end{array}$ \\
\hline
\end{tabular}

De acordo com BERNUCCI et al. [16] a temperatura de usinagem do ligante asfáltico é definida quando o mesmo possui uma viscosidade rotacional de $0,17 \pm 0,02$ Pa.s. $\mathrm{O}$ ligante não deve possuir temperatura inferior a $107^{\circ} \mathrm{C}$ nem superior a $177^{\circ} \mathrm{C}$ e a temperatura dos agregados deve ser de 10 a $15^{\circ} \mathrm{C}$ acima da temperatura determinada para o ligante, sem ultrapassar $177^{\circ} \mathrm{C}$. A temperatura de compactação da mistura asfáltica é definida quando o ligante apresenta viscosidade rotacional de 0,28 $\pm 0,03$ Pa.s. A Tabela 02 aponta os resultados das temperaturas de usinagem e compactação.

Tabela 2: Temperatura de usinagem e compactação.

\begin{tabular}{c|c}
\hline TEMPERATURA DE USINAGEM E COMPACTAÇÃo & CAP 50/70 \\
\hline Temperatura de usinagem do ligante $\left({ }^{\circ} \mathrm{C}\right)$ & 159 \\
\hline Temperatura de usinagem do agregado $\left({ }^{\circ} \mathrm{C}\right)$ & 169 \\
\hline Temperatura de compactação da mistura $\left({ }^{\circ} \mathrm{C}\right)$ & 145 \\
\hline
\end{tabular}




\subsubsection{Agregados naturais}

A pesquisa utilizou agregados graníticos, de graduação $19,0 \mathrm{~mm}, 12,5 \mathrm{~mm}$, pó de pedra e areia. A Tabela 03 apresenta a caracterização física dos agregados.

Tabela 3: Caracterização física dos agregados.

\begin{tabular}{c|c|c|c|c|c}
\hline \multirow{2}{*}{ ENSAIO } & NORMA & \multicolumn{3}{|c}{ AGREGADO } \\
& $\begin{array}{c}\text { BRITA } \\
\mathbf{1 9 . 0} \\
\mathbf{m m}\end{array}$ & $\begin{array}{c}\text { BRITA } \\
\mathbf{1 2 . 5} \\
\mathbf{m m}\end{array}$ & AREIA & $\begin{array}{c}\text { PÓ DE PE- } \\
\text { DRA }\end{array}$ \\
\hline $\begin{array}{c}\text { Massa específica real } \\
\left(\mathrm{g} / \mathrm{cm}^{3}\right)\end{array}$ & $\begin{array}{c}\text { ASTM } \\
\text { C127:2015 [17] }\end{array}$ & 2,53 & 2,56 & 2,38 & 2,43 \\
\hline $\begin{array}{c}\text { Massa Específica Aparente } \\
\left(\mathrm{g} / \mathrm{cm}^{3}\right)\end{array}$ & $\begin{array}{c}\text { ASTM } \\
\mathrm{C} 127: 2015[17]\end{array}$ & 2,52 & 2,51 & 2,39 & 2,42 \\
\hline
\end{tabular}

Os agregados utilizados em pavimentação devem possuir uma resistência ao desgaste. $\mathrm{O}$ ensaio de Abrasão Los Angeles mede esse desgaste que ocorre no agregado graúdo quando submetido a usinagem da mistura. A Tabela 04 apresenta os resultados obtidos nesse ensaio.

Tabela 4: Resultado do ensaio de abrasão "Los Angeles".

\begin{tabular}{c|c|c|c|c|c}
\hline \multirow{2}{*}{ ENSAIO } & \multirow{2}{*}{ NORMA } & \multicolumn{2}{|c|}{ REQUISITO } & \multicolumn{2}{c}{ AGREGADOS GRAÚDOS } \\
\cline { 3 - 5 } & & Mín & Máx & $\mathbf{1 9} \mathbf{~ m m}$ & $\mathbf{1 2 , 5} \mathbf{~ m m}$ \\
\hline Abrasão Los Angeles (\%) & ASTM & - & $50 \%$ & $31,33 \%$ & $25,40 \%$ \\
\hline
\end{tabular}

O ensaio de granulometria com os agregados em estudo foi realizado de acordo com a norma DNIT-ME 083/98 [19]. A distribuição granulométrica dos grãos dos agregados graúdos e miúdo é obtida, e a partir desses dados é gerada a curva granulométrica. O procedimento consiste no peneiramento dos grãos por uma série de peneiras objetivando determinar a percentagem em peso que cada faixa especificada de tamanhos de grãos representa na massa total ensaiada, possibilitando assim a obtenção da curva de distribuição dos tamanhos das partículas. A Figura 01 apresenta a curva granulométrica correspondente aos agregados utilizados na pesquisa. 


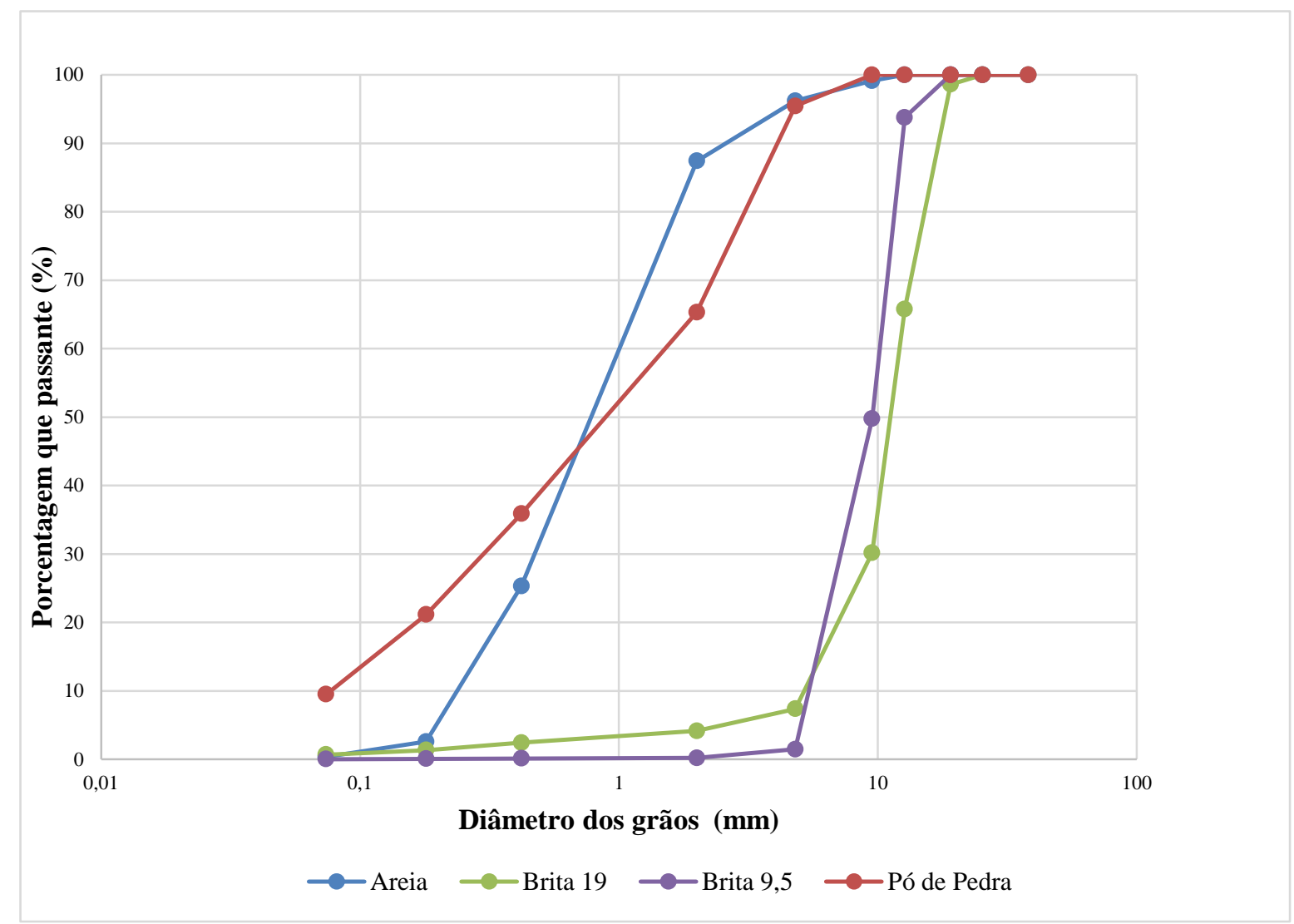

Figura 1: Curva granulométrica dos agregados graúdos e miúdos.

\subsection{3 Óxido Metálico}

O óxido de ferro trata-se de um pigmento inorgânico colorante e pulverulento, que possui alto poder de tingimento, extremamente resistente à ação da luz e intempéries. A Figura 02 apresenta os óxidos metálicos utilizados neste estudo e a coloração das misturas asfálticas com adição destes.

A)

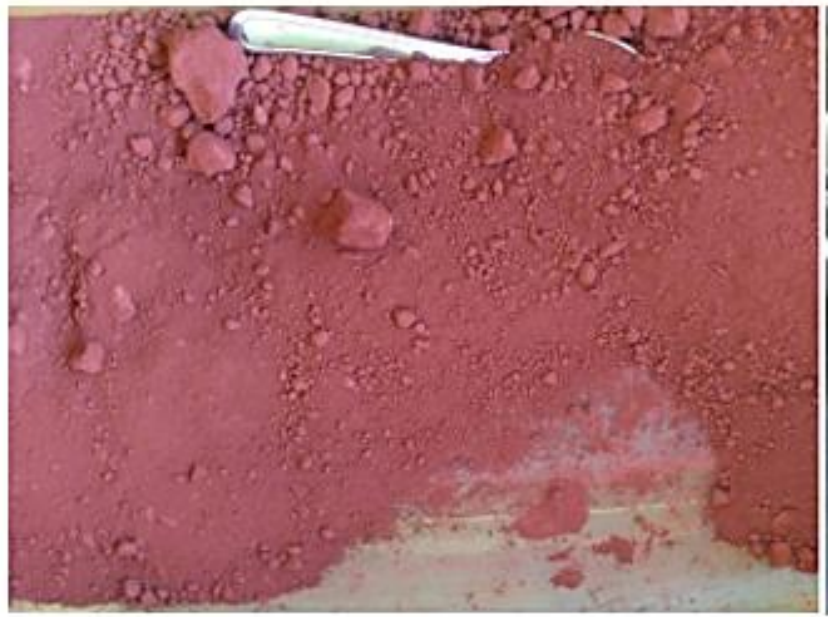

B)

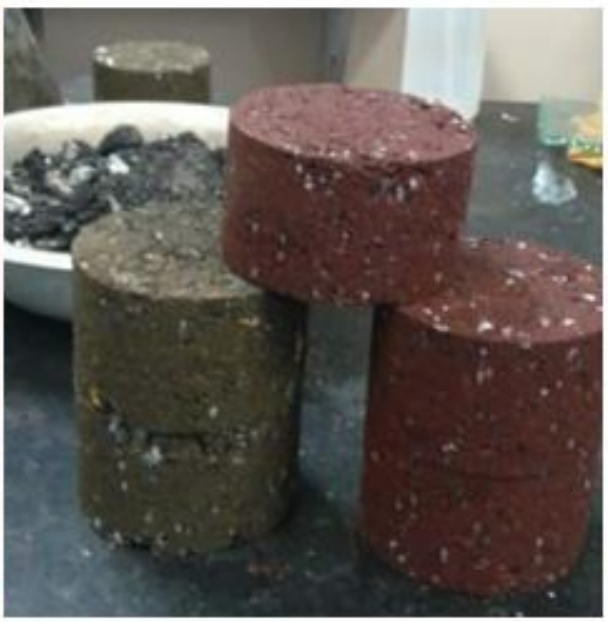

Figura 2: A) Óxido de ferro vermelho. B) Corpos de prova com adição de óxido de ferro amarelo e vermelho. 
O ensaio de Difração de Raio-X (DRX) foi realizado a fim de conhecer melhor as características físicas e químicas do óxido de ferro. Esse ensaio consiste no espalhamento da radiação eletromagnética, ocasionada pela interação entre o feixe de raios- $\mathrm{X}$ incidentes e os elétrons dos átomos componentes do material.

O método é utilizado para determinar a estrutura atômica e molecular de um cristal, no qual os átomos cristalinos fazem com que um feixe de raios- $X$ incidentes difrate em muitas direções específicas. A Figura 03 apresenta os resultados do ensaio dos pigmentos Amarelo e Vermelho.

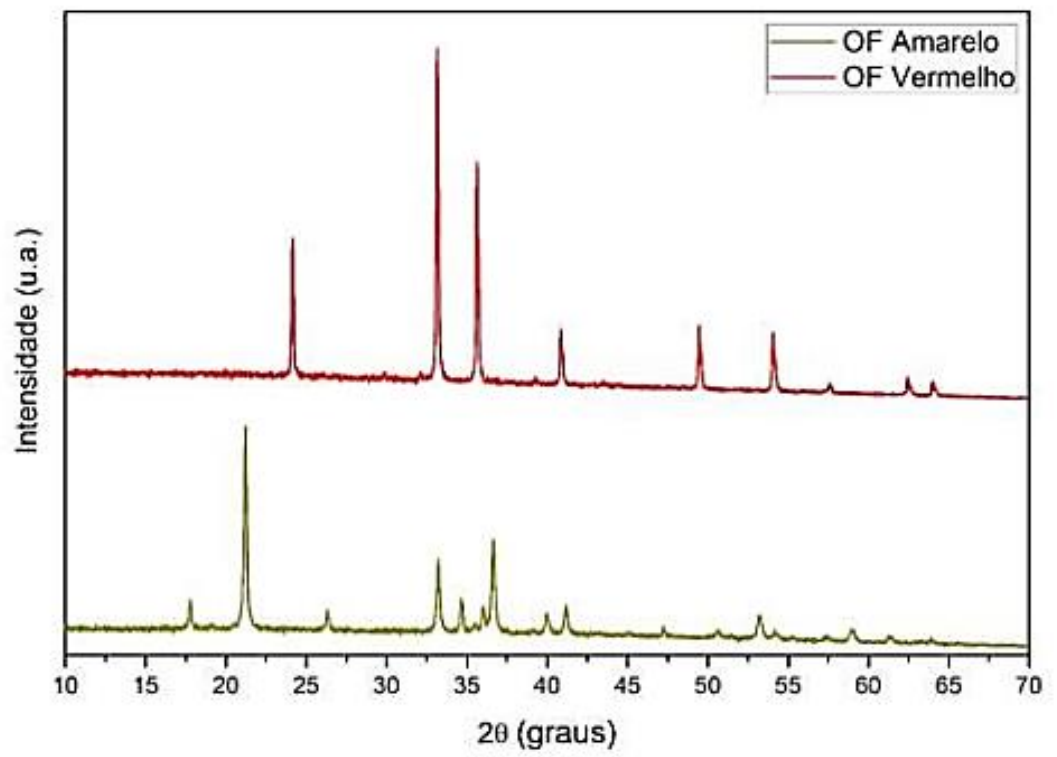

Figura 3: DRX dos pigmentos Vermelho e Amarelo.

Os resultados apontam que as amostras apresentam uma estrutura cristalina pouco amorfa, o que pode favorecer a baixa ou nenhuma reatividade destes óxidos com outros materiais. VILLENA [5] afirma em sua pesquisa que esses tipos de colorações são muito presentes em solos de clima tropical como o Brasil, tendo o óxido Amarelo similar a estrutura do mineral Goethite e o óxido Vermelho similaridade com a estrutura do mineral Hematita.

Na Figura 3 estão presentes os dois difratogramas para as amostras de corantes vermelho e amarelo. Para a amostra de cor vermelho, foram encontrados picos correspondentes ao óxido de ferro III $\left(\mathrm{Fe}_{2} \mathrm{O}_{3}\right)$, enquanto que para a amostra de cor amarelo correspondente ao óxido de ferro III hidratado $(\mathrm{FeO}(\mathrm{OH}))$. Ambas amostras possuem alto grau de pureza e não foram encontrados picos correspondentes a outros materiais cristalinos nestas.

A faixa angular prevista é de 3 a $70^{\circ}$, contudo no resultado aponta de 10 a $70^{\circ}$, esse fato é devido à inexistência de picos relevantes abaixo dessa faixa. VILLENA [5] utilizou a porcentagem de 4,0\% de óxido de ferro em suas misturas asfálticas; entretanto, nas suas sugestões para futuras pesquisas o mesmo sugere avaliar a influência da variação da proporção dos pigmentos dentro da mistura asfáltica nas propriedades mecânicas das mesmas, assim como que os ensaios de refletância solar em laboratório com uso de $2 \%$ a $6 \%$ do pigmento não alteraria significativamente o valor da refletância, ou seja, a utilização do teor dentro dessa faixa tende a apresentar também bons resultados.

PORTO [2] utilizou 5\% do pigmento metálico na produção de suas misturas asfálticas e KARAHANCER et al. [8] também aplicou 5\% dentre os teores definidos para adição das nanopartículas de óxido de ferro. Dessa forma, o teor de óxido metálico de ferro determinado para realização desta pesquisa foi de $5 \%$ por ter apresentado bons resultados na literatura.

\subsection{Métodos}

O programa experimental da pesquisa foi realizado em duas etapas: a primeira consiste no processo de dosagem Marshall da mistura asfáltica e a segunda etapa corresponde à análise das propriedades mecânicas das misturas. 


\subsubsection{Dosagem Marshall}

A dosagem Marshall, normatizada pelo DNIT-ME 043/95 [20], foi escolhida objetivando determinar o teor ótimo de ligante asfáltico para uma curva granulométrica pré-definida. Após obter os resultados de massa especifica dos agregados, selecionou-se a faixa granulométrica a ser usada para confecção dos corpos de prova, enquadrando a mesma na curva de Fuller seguindo as especificações da faixa C estabelecida pelo DNIT.

Como se se trabalhou com três misturas diferentes as mesmas foram denominadas: inferior, intermediária e superior. A Figura 04 apresenta a curva intermediária, que é aquela em que a combinação dos agregados fornece uma distribuição granulométrica que não se apresenta próxima aos limites impostos pelos pontos de controle nem da zona de restrição.

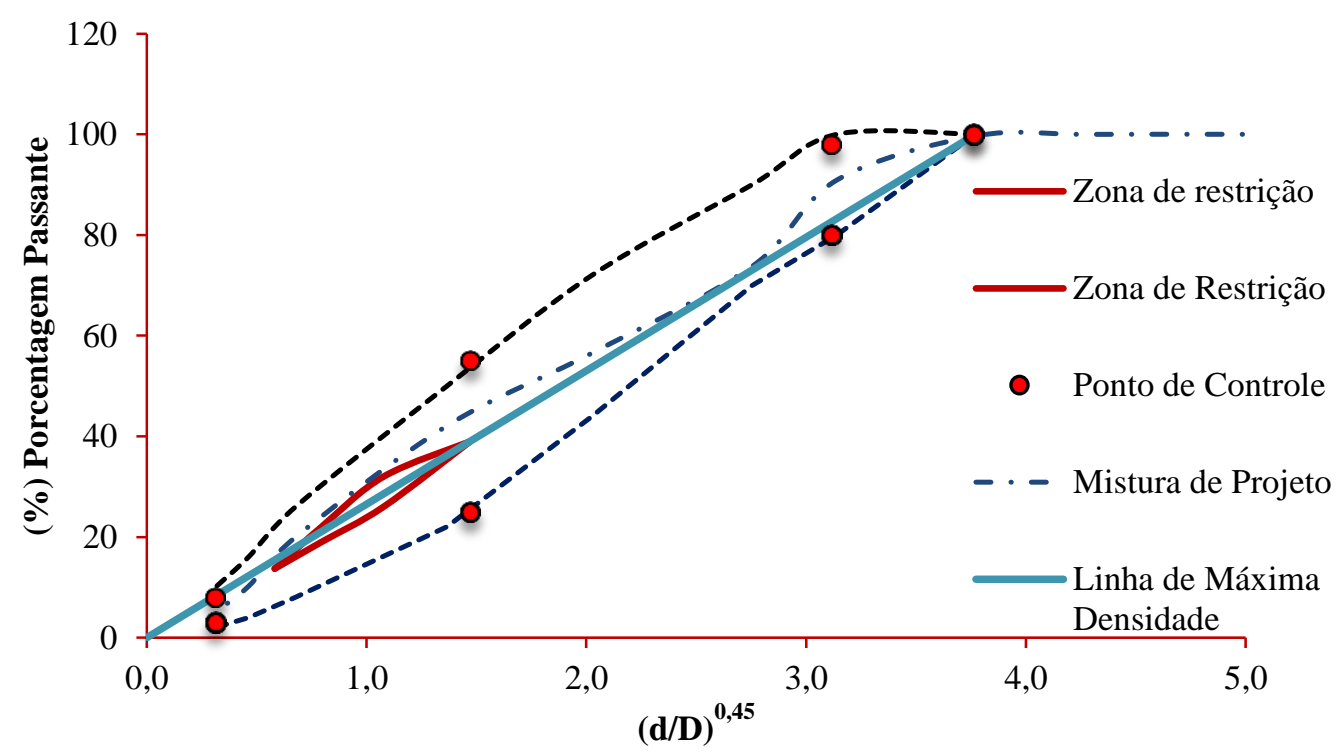

Figura 4: Curva de Fuller da Mistura intermediária para a Faixa C do DNIT.

A partir da escolha da faixa, foi possível a escolha da composição dos agregados utilizados na mistura. Para a realização da dosagem, o agregado e ligante foram aquecidos separadamente até a temperatura de $169^{\circ} \mathrm{C}$ e $159^{\circ} \mathrm{C}$, respectivamente. Posteriormente, foram misturados mantendo-se a temperatura de mistura $\left(145^{\circ} \mathrm{C}\right)$, ambas foram previamente determinadas no ensaio de viscosidade (Tabela 2). Em seguida, a mistura foi colocada em um molde e compactada com um soquete caindo de uma altura determinada, e quinze corpos de prova foram moldados, sendo três para cada teor de ligante asfáltico testado. Nesta pesquisa, adotaram-se os teores iniciais de 3,5\%,4,0\%, 4,5\%,5,0\% e 5,5\% de CAP 50/70. Os corpos de provas fabricados com teor de projeto de $5 \%$, obtido por meio da dosagem Marshall, foram submetidos a ensaios que permitiram avaliar suas propriedades mecânicas.

\subsubsection{Ensaios Mecânicos}

O ensaio de Resistência à Tração por Compressão Diametral (RT) foi realizado seguindo as especificações da norma DNIT-ME 136/10 [21]. Inicialmente foi medido três diâmetros paralelos e quatro alturas diametralmente opostas do corpo de prova, com um paquímetro obteve-se a média dos valores correspondentes, respectivamente ao diâmetro e à altura. $\mathrm{O}$ corpo de prova foi colocado em estufa até obter a temperatura $25^{\circ} \mathrm{C} \pm$ $0,1^{\circ} \mathrm{C}$, posteriormente o corpo de prova foi posicionado em uma superfície cilíndrica entre dois frisos metálicos. Quando ajustados os pratos para exercer uma leve compressão capaz de manter o corpo de prova, aplicou-se a carga progressivamente com uma velocidade de deformação de $0,8 \pm 0,1 \mathrm{~mm} / \mathrm{s}$, até que se deu a ruptura por separação das duas metades do corpo de prova segundo o plano diametral vertical, obtendo-se a carga de ruptura que determina a tensão máxima suportada pela mistura asfáltica antes de romper.

Ao aplicar uma carga cíclica, obtém-se uma relação entre tensão horizontal e deformação horizontal que resulta do deslocamento horizontal recuperável. Essa deformação elástica ou recuperável das camadas de pavimentos submetidos a carregamentos repetidos é chamada de deformação resiliente. O ensaio de Módulo de Resiliência (MR) normatizado pela norma DNIT-ME 135/17 [22], foi realizado na prensa hidráulica 
UTM-25 da IPC na qual os corpos de prova cilíndricos de aproximadamente $10 \mathrm{~cm}$ de diâmetro por $6,5 \mathrm{~cm}$ de altura foram posicionados em um molde e, em seguida, foi aplicada uma carga compressiva em formato de onda pulsante. Aplicou-se uma carga igual a 10\% do valor da resistência à tração, numa frequência de 60 ciclos por minuto $(1 \mathrm{~Hz})$, com tempo de aplicação de $0,1 \mathrm{~s}$ e $0,9 \mathrm{~s}$ de repouso ou descarregamento.

O ensaio de Estabilidade Marshall é realizado segundo a norma DNIT-ME 043/95 [20] e mede a resistência máxima em $\mathrm{N}$ (Kgf), a compressão diametral, de um corpo de prova ensaiado segunda a norma. A importância desse ensaio está no fato de que a mistura deve ter resistência ao cisalhamento compatível com os esforços que serão aplicados a ela. O procedimento iniciou-se com a imersão dos corpos de prova em banho-maria, por um período de 30 a 40 minutos, em seguida cada corpo de prova foi colocado em um molde de compressão que estava na temperatura de $60^{\circ} \mathrm{C}$. O molde de compressão, contendo o corpo de prova, é posicionado na prensa segundo a geratriz, e o medidores de fluência são colocados e ajustados na posição de ensaio. A prensa é operada de tal modo que seu êmbolo se eleve a uma velocidade de $5 \mathrm{~cm}$ por minuto, até o rompimento do corpo de prova, o que é observado no defletômetro pela indicação de um máximo.

\section{RESULTADOS E ANÁLISE}

Nesta seção estão apresentados e discutidos os resultados obtidos na fase experimental das misturas asfálticas modificadas com o óxido metálico de ferro.

\subsection{Resistência à Tração por Compreensão Diametral (RT)}

Neste estudo foram realizados três tipos de misturas, a convencional com o CAP puro, a colorida com adição de corante vermelho e a mistura com adição de corante amarelo. A Tabela 05 apresenta os resultados do ensaio de Resistência à Tração por Compressão Diametral para as misturas asfálticas coloridas e a de referência.

Tabela 5: Resultados de Resistência à Tração das Misturas Asfálticas.

\begin{tabular}{c|c|c|c|c|c}
\hline $\begin{array}{c}\text { CAP COM CORANTE } \\
\text { (VERMELHO) }\end{array}$ & $\begin{array}{c}\mathbf{R T} \\
(\mathbf{M P a})\end{array}$ & $\begin{array}{c}\text { CAP COM CORANTE } \\
\text { (AMARELO) }\end{array}$ & $\begin{array}{c}\mathbf{R T} \\
\text { (MPa) }\end{array}$ & $\begin{array}{c}\text { CAP } \\
\text { PURO }\end{array}$ & $\begin{array}{c}\mathbf{R T} \\
(\mathbf{M P a})\end{array}$ \\
\hline I & 0,87 & I & 0,69 & I & 0,92 \\
II & 0,86 & II & 0,61 & II & 0,84 \\
III & 0,87 & III & 0,51 & III & 0,89 \\
Média & 0,87 & Média & 0,61 & Média & 0,88 \\
\hline
\end{tabular}

De acordo com a norma do DNIT-ES 031/2006 [23], o valor mínimo para resistência à tração é de 0,65 MPa para camadas de rolamento. Conforme a Tabela 05, todos os resultados obtidos foram superiores ao mínimo exigido pelo DNIT, observa-se também que a adição de corante não aumentou a resistência à tração.

KARAHANCER et al. [8] apontam, em seu estudo, que a adição de nanopartículas de óxido de ferro nos teores de $1 \%, 3 \%$ e 5\% favoreceram o aumento de resistência à tração por compressão diametral da mistura asfáltica em relação à mistura convencional. As nanopartículas ao interagirem com o ligante asfáltico resultou no incremento de rigidez e, consequentemente, no aumento da resistência à tração. $\mathrm{O}$ estudo de PORTO [9] corrobora com os resultados apresentados por KARAHANCER et al. [8], em que foi observado valores maiores de resistência à tração nos corpos de prova modificados com corantes em relação à mistura asfáltica de referência.

VILLENA [5], em sua pesquisa, observou um aumento de 29,17\% do valor de resistência à tração da mistura colorida em relação à mistura convencional. Enquanto que nos ensaios realizados neste trabalho pôde-se observar na Tabela 05 que a resistência à tração da mistura colorida vermelha diminuiu 1,14\% em relação à amostra de referência e a mistura colorida amarela reduziu 30,7\% quando comparada à convencional. No entanto, isso não comprometeu a resistência, pois atende aos requisitos mínimos estabelecidos por norma para camadas de rolamento.

O comportamento distinto do esperado pode ter sido ocasionado por diversos fatores, dentre eles pode-se citar erros na hora da realização da compactação. Um fator importante é que em seu trabalho, VILLENA [5], adicionou 4\% de corante ponderando com todos os outros componentes, inclusive com teor de ligante ótimo, fato que não ocorreu nessa pesquisa e que pode ter comprometido os parâmetros mecânicos da mistura, deixando-a com muitos finos. 


\subsection{Módulo de Resiliência (MR)}

A Tabela 06 apresenta os resultados obtidos no ensaio de Módulo de Resiliência para as misturas asfálticas convencional (CAP puro) e coloridas, ensaiadas a uma temperatura de $25^{\circ} \mathrm{C}$. As misturas asfálticas foram analisadas em um número de três corpos de prova para cada tipo estudado, e a média dos resultados calculada.

Tabela 6: Resultados do Módulo de Resiliência.

\begin{tabular}{c|c|c|c|c|c}
\hline $\begin{array}{c}\text { CAP COM CORANTE } \\
\text { (VERMELHO) }\end{array}$ & $\begin{array}{c}\text { MR } \\
\text { (MPa) }\end{array}$ & $\begin{array}{c}\text { CAP COM CORANTE } \\
\text { (AMARELO) }\end{array}$ & $\begin{array}{c}\text { MR } \\
\text { (MPa) }\end{array}$ & $\begin{array}{c}\text { CAP } \\
\text { PURO }\end{array}$ & $\begin{array}{c}\text { MR } \\
\text { (MPa) }\end{array}$ \\
\hline I & 3915 & I & 1874 & I & 4342 \\
II & 5116 & II & 3439 & II & 5742 \\
III & 4535 & III & 4753 & III & 6055 \\
Média & 4522 & Média & 3355 & Média & 5379 \\
\hline
\end{tabular}

No estudo de VILLENA [5] os valores apresentados para Módulo de Resiliência nas misturas asfálticas modificadas com corantes de óxido de ferro foram superiores à mistura convencional, assim como na pesquisa de PORTO [2]. Ambos os estudos apresentaram valores de Módulo de Resiliência dentro e acima do intervalo que normalmente apresentam as misturas asfálticas densas (VILLENA) [5].

Segundo BERNUCCI et al. [16] os valores de Módulo de Resiliência para misturas asfálticas densas devem se encontrar numa faixa de 2000 a 8000 MPa. Na presente pesquisa os valores de Módulo de Resiliência não aumentaram em relação à mistura de referência, e os resultados obtidos apresentaram-se dentro da faixa usual acima citada. Com base na Tabela 06, observa-se que o valor do Módulo de Resiliência para a mistura com corante vermelho reduziu, aproximadamente, $16 \%$ em relação à mistura convencional e o CAP com corante amarelo reduziu 37,6\% quando comparado à mesma. As possíveis causas para a diminuição do valor do Módulo Resiliente são as mesmas citadas no ensaio de Resistência à Tração: erros na realização da compactação Marshall.

\subsection{Relação Módulo de Resiliência/Resistência à Tração por Compressão Diametral (MR/RT)}

A partir dos dados adquiridos nos ensaios de Módulo de Resiliência e Resistência à Tração por Compressão Diametral, projetou-se a Tabela 07 que apresenta a relação entre esses dois parâmetros, denominada de Relação MR/RT. A razão permite analisar o comportamento das misturas asfálticas ao trincamento, pois quanto menor o valor da razão maior a tendência de melhora no comportamento mecânico das misturas, porque une flexibilidade a uma boa resistência à tração. A redução no valor dessa razão pode proporcionar a utilização de espessuras menores da camada de revestimento, levando em conta a mesma vida de fadiga (SANTOS et al.) [24].

Tabela 7: Resultados do Módulo de Resiliência e da Resistência à Tração por Compressão Diametral.

\begin{tabular}{c|c|c|c}
\hline TIPO & MÓDULO DE RESILIÊNCIA (MPa) & $\begin{array}{c}\text { RESISTÊNCIA À } \\
\text { TRAÇÃO (MPa) }\end{array}$ & $\begin{array}{c}\text { RELAÇ̃̃O } \\
\text { MR/RT }\end{array}$ \\
\hline CAP Puro & 5379,00 & 0,88 & 6112,50 \\
\hline CAP + Corante Vermelho & 4522,00 & 0,87 & 5197,70 \\
\hline CAP + Corante Amarelo & 3355,00 & 0,61 & 5500,00 \\
\hline
\end{tabular}

De acordo com TEBALDI [25] a relação entre esses dois parâmetros, módulo de resiliência e resistência à tração vem sendo utilizada como um indicador da vida de fadiga das misturas asfálticas, porque analisa a relação entre rigidez e resistência. BOEIRA [26] aponta que misturas com altos valores de Módulo de Resiliência requerem altos valores de Resistência à Tração devido à concentração de esforços presentes no seu interior.

Os resultados demonstram que a relação MR/RT encontra-se na faixa de 5000 a 6200 . O menor valor é de 5197 (CAP com corante vermelho). PINHEIRO et al. [27] aponta que o valor de 3000 na razão MR/RT indica uma mistura com bom comportamento estrutural. Contudo, este parâmetro não tem validade para todos os tipos de materiais. 


\subsection{Estabilidade Marshall}

A Tabela 08 apresenta os resultados do ensaio de Estabilidade Marshall para as misturas asfálticas analisadas, e as médias dos três corpos de provas avaliados em cada tipo de mistura.

Tabela 8: Resultados de Estabilidade Marshall.

\begin{tabular}{c|c|c|c|c|c}
\hline $\begin{array}{c}\text { CAP COM CORANTE } \\
\text { (VERMELHO) }\end{array}$ & Kgf & $\begin{array}{c}\text { CAP COM CORANTE } \\
\text { (AMARELO) }\end{array}$ & Kgf & $\begin{array}{c}\text { CAP } \\
\text { PURO }\end{array}$ & Kgf \\
\hline I & 651 & I & 756 & I & 1144 \\
II & 592 & II & 527 & II & 296 \\
III & 493 & III & 486 & III & 720 \\
Média & 579 & Média & 590 & Média & 720 \\
\hline
\end{tabular}

A norma DNIT-ES 031/2006 [23] estabelece que os valores mínimos de Estabilidade Marshall para camada de revestimento é $500 \mathrm{Kgf}$, como pode ser observado na Tabela 08 tanto para a mistura de referência quanto para as misturas coloridas, os resultados de estabilidade Marshall foram superiores aos exigidos por norma. Os valores das amostras com corante quando comparados ao da amostra de referência apresentam redução da ordem de $19,6 \%$ para o CAP com corante vermelho e 18\% para o CAP com corante amarelo.

\section{CONCLUSÕES}

A adição de óxido metálico ocasionou redução da Resistência à Tração por Compressão Diametral Indireta das misturas asfálticas. O CAP modificado com óxido metálico vermelho apresentou valor bem próximo da mistura de referência, enquanto o modificado com corante amarelo apresentou uma redução de 30,7\% em relação à convencional. Apesar disso, todas as misturas estudadas (modificadas ou não) apresentaram-se acima do mínimo preconizado pela especificação de serviço do DNIT.

Para os resultados obtidos no ensaio de Módulo de Resiliência das misturas asfálticas estudadas, observou-se uma diminuição no valor para o CAP modificado com óxido metálico vermelho de $16 \%$ e uma redução de $37,6 \%$ da mistura com corante amarelo quando comparados à mistura de referência. Contudo, todas as amostras apresentaram-se dentro dos limites especificados.

Os valores da relação MR/RT para as misturas asfálticas modificadas foram inferiores ao da mistura convencional, apontando boa resistência ao trincamento. Esse menor valor da razão MR/RT indica uma tendência maior de melhora no comportamento mecânico das misturas asfálticas.

Todas as misturas asfálticas estudadas apresentaram Estabilidade Marshall acima dos valores mínimos exigidos pelas normas, no entanto as misturas modificadas com corante apresentaram desempenho inferior ao observado na convencional.

De modo geral, os parâmetros mecânicos das misturas modificadas com óxido metálico de ferro sofreram uma diminuição. Todavia, essa redução não impede o seu uso em pavimentos, uma vez que todos os parâmetros avaliados foram superiores aos exigidos em norma.

A realização de outros ensaios mecânicos como Módulo Dinâmico, Flow Number e Resistência à Fadiga podem melhorar a caracterização mecânica dessas amostras, assim como o enquadramento da curva granulométrica em uma proporção menor de finos devido à granulometria do óxido metálico.

\section{AGRADECIMENTOS}

À Universidade Federal de Campina Grande - UFCG, pela disponibilização do laboratório de Engenharia de Pavimentos - LEP no qual foram realizados os procedimentos experimentais desse trabalho e à CNPq, pela concessão da bolsa de estudos ao longo do curso de mestrado.

\section{BIBLIOGRAFIA}

[1] VILLENA, J., TRICHÊS, G., MARINOSKI, D., et al. "Deformação Permanente de Misturas Asfálticas com Pigmentos de Óxidos Metálicos Mistos", In: "44 Reunião Anual de Pavimentação", Foz do Iguaçu, Paraná, 18-28 agosto de 2015.

[2] PORTO, T.R., "Utilização do óxido de ferro em misturas asfálticas objetivando reduzir os efeitos das 
Ilhas de Calor Urbano", Dissertação de M.Sc., UFCG, Campina Grande, PB, Brasil, 2019.

[3] SANTAMOURIS, M., "Using cool pavements as a mitigation strategy to fight urban heat island-A review of the actual developments", Renewable and Sustainable Energy Reviews, v. 26, pp. 224-240, Oct. 2013.

[4] SANTAMOURIS, M., DING, L., FIORITO, F., et al. "Passive and active cooling for the outdoor built environment - Analysis and assessment of the cooling potential of mitigation technologies using performance data from 220 large scale projects", Solar Energy, v. 154, pp. 14-33, Sep. 2017.

[5] LIU, H.Y., ZHANG, H.L., HAO, P.W., et al. "The Effect of Surface Modifiers on Ultraviolet Aging Properties of Nano-zinc Oxide Modified Bitumen”, Petroleum Science and Technology, v. 33, pp. 72-78, Oct. 2015.

[6] VILLENA, J., Uso de pigmentos de óxidos de metais mistos na pavimentação para a mitigação da Ilha de Calor Urbana, Tese de D.Sc., UFSC, Florianópolis, SC, Brasil, 2014.

[7] SHEETHU, J., JOSHY, D., NARENDRANATH, S.B., PERIYAT, P. "Recent advances in infrared reflective inorganic pigments", Solar Energy Materials and Solar Cells, v. 194, pp. 7-27, Jun. 2019.

[8] KARAHANCER, S., "Investigating the performance of cuprous oxide nano particle modified asphalt binder and hot mix asphalt", Construction and Building Materials, v. 212, pp. 698-706, Jul. 2019.

[9] KARAHANCER, S., ENIEB, M., SALTAN, M., et al. "Evaluating mechanical properties of bitumen and hot mix asphalt modified with nano ferric oxide", Construction and Building Materials, v. 234, pp. 117381, Feb. 2020.

[10] MOUSAVI, S.M., HASHEMI, S.A., BABAPOOR, A., et al. "Enhancement of Rheological and Mechanical Properties of Bitumen by Polythiophene Doped with Nano Fe3O4", The Journal of The Minerals, Metals \& Materials Society (TMS), v. 71, pp. 531-540, Feb. 2019.

[11] DNIT: Departamento Nacional de Infraestrutura e Transportes, PRO 199 - Redução de amostra de campo de agregados para ensaio de laboratório, Norma Rodoviária, Rio de Janeiro, 1996.

[12] DNIT: Departamento Nacional de Infraestrutura e Transportes, EM 095 - Cimentos asfálticos de petróleo, Especificação de material, Rio de Janeiro, 1996.

[13] ASTM: American Society for Testing and Materials - D 5, Standard Test Method for Penetration of Bituminous Materials, USA, 2019.

[14] ASTM: American Society for Testing and Materials - D 36, Standard Test Method for Softening Point of Bitumen (Ring-and-Ball Apparatus), USA, 2014.

[15] ASTM: American Society for Testing and Materials - D 4402, Standard Test Method for Viscosity Determination of Asphalt at Elevated Temperatures Using a Rotational Viscometer, USA, 2015.

[16] BERNUCCI, L.B., MOTTA, L.M.G., CERATTI, J.A.P., et al.Pavimentação Asfáltica: Formação Básica para Engenheiros, Rio de Janeiro, ABDEA, 2008.

[17] ASTM: American Society for Testing and Materials - C 127, Standard Test Method for Relative Density (Specific Gravity) and Absorption of Coarse Aggregate, USA, 2015.

[18] ASTM: American Society for Testing and Materials - C 131, Standard Test Method for Resistance to Degradation of Small-Size Coarse Aggregate by Abrasion and Impact in the Los Angeles Machine, USA, 2020.

[19] DNIT: Departamento Nacional de Infraestrutura e Transportes, ME 083 - Agregados, Análise granulométrica, Rio de Janeiro, 1998.

[20] DNIT: Departamento Nacional de Infraestrutura e Transportes, ME 043 - Misturas betuminosas à quente, Ensaio Marshall, Rio de Janeiro, 1995.

[21] DNIT: Departamento Nacional de Infraestrutura e Transportes, ME 136 - Misturas asfálticas, Determinação da resistência à tração por compressão diametral, Rio de Janeiro, 2010.

[22] DNIT: Departamento Nacional de Infraestrutura e Transportes, ME 135 -Pavimentação asfáltica, Misturas asfálticas, Determinação do módulo de resiliência, Método de ensaio, Rio de Janeiro, 2017.

[23] DNIT: Departamento Nacional de Infraestrutura e Transportes, ES 031 - Pavimentos flexíveis, Concreto asfáltico, Especificação de serviço, Rio de Janeiro, 2006.

[24] SANTOS, K.P., LUCENA, A.E.F.L., LUCENA, L.C.F.L., et al. "Estudo da incorporação de argilas montmorilonitas em cimentos asfálticos de petróleo", Revista Matéria, v. 20, n. 02, pp. 501-513, 2015.

[25] TEBALDI, P.D., Verificação da dosagem e do comportamento mecânico do concreto asfáltico: estudo de caso, Trabalho de Conclusão de Curso, UFSM, Santa Maria, RS, Brasil, 2016. 
[26] BOEIRA, F.D., "Estudo do desempenho de concretos asfálticos com diferentes tipos de agregados e cales”, Dissertação de M.Sc, UFSM, Santa Maria, RS, Brasil, 2014.

[27] PINHEIRO, J.H.M., SOARES, J.B., LEITE, L.F.M., “Caracterização de misturas asfálticas com borracha produzidos pelos processos úmido e seco", In: XVII ANPET - Congresso de Pesquisa e Ensino em Transporte, pp. 116-129, Rio de Janeiro, 2003.

\section{ORCID}

Flávia do Socorro de Sousa Carvalho

http://orcid.org/0000-0003-0248-2990

Adriano Elísio de Figueiredo Lopes Lucena

http://orcid.org/0000-0002-5348-1683

Osires de Medeiros Melo Neto

http://orcid.org/0000-0002-2535-0969

Tassila Ramos Porto

https://orcid.org/0000-0002-3682-8147

Thalita Maria Ramos Porto

https://orcid.org/0000-0002-5864-6440 